\title{
PERAN RELAWAN DALAM PENANGGULANGAN BENCANA ERUPSI GUNUNG KELUD
}

\author{
Agus Khoirul Anam, Sri Winarni, Sylvia Rosi Andriani \\ Poltekkes Kemenkes Malang, Jalan Besar Ijen No 77 C Malang \\ Email:Aguskhoirulanam@gmail.com
}

\section{Role of Indonesian Red Cross Volunteer In Tackling Kelud Eruption Disaster}

\begin{abstract}
In the tackling of disaster is required the role of volunteer when dusaster is not happened, is happening, and after happened. The purpose of this research is to know role of indonesian red cross volunteer in the tackling of Kelud eruption in Blitar. The population was all Indonesian Red Cross volunteer in Blitar regency even Tenaga Sukarela (TSR) or Korps Sukarela (KSR) in 2016 as 150 volunteer and the sample was taken as 30 people using Purposif Sampling. the result showed that $60 \%$ Indonesian Red Cross volunteer had enough role in tackling Mount Kelud eruption in Blitar Regency. The role of Indonesian Red Cross volunteer when not eruption is enough catagorized as 50\%, when erupting is well catagorized as $63,3 \%$ and pasca eruption is less catagorized as $56,7 \%$.
\end{abstract}

Keywords: role, volunteer, disaster, eruption

\begin{abstract}
Abstrak: Dalam penanggulangan bencana diperlukan peran relawan pada saat tidak terjadi bencana, saat terjadi bencana, dan pasca bencana. Penelitian ini bertujuan untuk mengetahui peran relawan PMI dalam penanggulangan bencana erupsi Gunung Kelud di Kabupaten Blitar. Metode penelitian menggunakan rancangan deskriptif. Populasi dalam penelitian adalah semua relawan PMI Kabupaten Blitar baik tenaga sukarela (TSR) maupun kors sukarela (KSR) pada tahun 2016 sebanyak 150 relawan dan besar sampel yang diambil adalah sebanyak 30 orang menggunakan teknik Purposif Sampling. Dari hasil analisis menunjukkan bahwa $60 \%$ relawan PMI memiliki peran cukup dalam penanggulangan bencana erupsi Gunung Kelud di Kabupaten Blitar. Peran relawan PMI pada saat tidak terjadi erupsi dikategorikan cukup yaitu 50\%, pada saat terjadi erupsi dikategorikan baik yaitu 63,3\%, dan pasca erupsi dikategorikan kurang yaitu 56,7\%.
\end{abstract}

Kata Kunci: peran, relawan, bencana, erupsi

\section{PENDAHULUAN}

Indonesia menjadi negara yang paling rawan terhadap bencana di dunia berdasarkan data yang dikeluarkan oleh Badan Perserikatan Bangsa-Bangsa untuk Strategi Internasional Pengurangan Resiko Bencana (UN-ISDR). Provinsi Jawa Timur memiliki sebuah gunung berapi yang tergolong aktif yaitu Gunung Kelud. Gunung ini berada di perbatasan antara Kabupaten Kediri, Kabupaten Blitar, dan Kabupaten Malang, $\pm 27 \mathrm{~km}$ sebelah timur pusat Kota Kediri. Sebagaimana Gunung Merapi, Gunung Kelud merupakan salah satu gunung berapi paling aktif di Indonesia. Letusan terakhir Gunung Kelud terjadi pada tahun 2014 (id.wikipedia.org diakses pada tanggal 20 September 2015).

Wilayah terdampak letusan Gunung Kelud di Kabupaten Blitar sebanyak empat kecamatan yaitu tiga desa di Kecamatan Ponggok, empat desa di Kecamatan Nglegok, tiga desa di Kecamatan Garum dan tujuh desa di Kecamatan Gandusari. Terdapat 16 desa yang terdampak secara langsung dalam radius 5-10 km dari puncak Gunung Kelud. Berdasarkan data Sensus Penduduk 2010 yang dilakukan oleh BPS, 16 desa terdampak yang berada di 4 (empat) kecamatan di Kabupaten Blitar dihuni oleh lebih 
dari 115 ribu penduduk. Warga mengungsi ditempat yang telah ditentukan sebelumnya yang tersebar di 63 titik evakuasi yang telah disepakati. Jumlah pengungsi di 63 lokasi pengungsian pada saat erupsi Gunung Kelud tersebar di 4 (empat) kecamatan mencapai 32.846 jiwa (Gema BNPB, Volume 5 Nomor 1, 2014). Desa Karangrejo merupakan desa paling utara di Kecamatan Garum Kabupaten Blitar. Desa Karangrejo berjarak $\pm 10 \mathrm{~km}$ dari Gunung Kelud sehingga desa tersebut termasuk dalam kawasan rawan bencana erupsi Gunung Kelud (BNPB, 2014).

Undang-Undang Penanggulangan Bencana nomor 24 tahun 2007 menyatakan pemerintah pusat dan pemerintah daerah menjadi penanggung jawab dalam penyelenggaraan penanggulangan bencana meliputi pengurangan risiko bencana dan pemaduan pengurangan risiko bencana dengan program pembangunan, perlindungan masyarakat dari dampak bencana, penjaminan pemenuhan hak masyarakat dan pengungsi yang terkena bencana secara adil dan sesuai dengan standar pelayanan minimum, dan pemulihan kondisi dari dampak bencana melalui Badan Nasional Penanggulangan Bencana.

Penyelenggaraan penanggulangan bencana bertujuan untuk menjamin terselenggaranya pelaksanaan penanggulangan bencana secara terencana, terpadu, terkoordinasi, dan menyeluruh dalam rangka memberikan perlindungan kepada masyarakat dari ancaman, risiko, dan dampak bencana. Penyelenggaraan penanggulangan bencana meliputi tahap pra bencana, saat tanggap darurat, dan pascabencana (Peraturan Pemerintah nomor 21 tahun 2008).

Pemerintah tentunya tidak dapat bekerja sendiri dalam penyelenggaraan penanggulangan bencana. Pasal 27 UU Penanggulangan Bencana nomor 24 tahun 2007 menegaskan bahwa setiap orang berkewajiban untuk melakukan kegiatan penanggulangan bencana. UU ini juga mengatur keterlibatan pihak swasta, lembaga-lembaga non-pemerintah dan lembaga internasional dalam penanggulangan bencana. Masyarakat dan pihak non-pemerintah dapat berpartisipasi dalam berbagai bentuk kerelawanan dalam penanggulangan bencana dan pengurangan risiko bencana. Agar keterlibatan para pemangku kepentingan dapat terarah dan terkoordinasi, perlu dirumuskan aturan-aturan bagi kerja relawan dalam penanggulangan bencana. Aturan yang dituangkan dalam bentuk pedoman ini akan mengatur peran, hak dan kewajiban relawan dalam menjalankan fungsi kerelawanan pada saat tidak terdapat bencana, dalam masa tanggap darurat, dan saat rehabilitasi-rekonstruksi pasca bencana (Peraturan Kepala Badan Nasional Penanggulangan Bencana Nomor 17 tahun 2011).

Relawan Penanggulangan Bencana, yang selanjutnya disebut relawan merupakan seorang atau sekelompok orang yang memiliki kemampuan dan kepedulian untuk bekerja secara sukarela dan ikhlas dalam upaya penanggulangan bencana. Sesuai dengan Peraturan Kepala Badan Nasional Penanggulangan Bencana nomor 17 tahun 2011 tentang Pedoman Relawan Penanggulangan Bencana, peran relawan dalam penyelenggaraan penanggulangan bencana terdiri dari peran relawan pada pra bencana yaitu mendukung penyusunan kebijakan perencanaan, pengurangan resiko bencana, upaya pencegahan dan kesiapsiagaan, dan peningkatan kapasitas bagi masyarakat, peran relawan pada saat tanggap darurat yaitu mendukung kegiatan pada tanggap darurat seperti ransum dan evaluasi, kesehatan, pendidikan darurat, logistik dan lainlain serta peran relawan pada saat pasca bencana seperti perbaikan darurat dan pemulihan psikososial. Dengan peran yang baik dari relawan tentunya penanggulangan bencana dapat dilaksanakan secara cepat, tepat, terpadu, efektif, efisien, transparan dan bertanggung jawab.

Relawan yang ada di gunung berapi memiliki peranan penting dalam penanggulangan bencana 
yaitu memberikan cara meredam ancaman gunung berapi antara lain dalam membantu kelancaran penyebaran informasi bahaya, efektifitas evakuasi ke tempat yang paling aman. Pada saat tanggap darurat relawan dapat menjadi pusat informasi mengenai status gunung berapi dari BNPB dan memastikan bahwa semua warga di area terdampak dalam kondisi aman dari ancaman bahaya (Sarwidi, 2010).

Hasil studi pendahuluan di Palang Merah Indonesia Kabupaten Blitar, tercatat ada 150 relawan yang terdiri dari tenaga sukarela (TSR) dan korps sukarela (KSR) yang pernah menjadi bagian dari relawan yang pernah berperan serta dalam penanggulangan bencana erupsi Gunung Kelud pada tahun 2014 yang tergabung dalam timPMI Jatim. Sedangkan di kota Blitar, tercatat ada 10 relawan.

Tujuan penelitian ini untuk mengetahui peran relawan dalam penyelenggaraan penanggulangan bencana erupsi Gunung Kelud di Kabupaten Blitar.

\section{METODE PENELITIAN}

Desain yang digunakan dalam penelitian ini adalah desain penelitian deskriptif. Dalam hal ini peneliti ingin menggambarkan peran relawan dalam penanggulangan bencana erupsi gunung Kelud di Kabupaten Blitar. Populasi dalam penelitian ini adalah semua relawan PMI Kabupaten Blitar baik tenaga sukarela (TSR) maupun korps sukarela (KSR) pada tahun 2016 sebanyak 150 relawan. Sampel dalam penelitian ini adalah relawan PMI Kabupaten Blitar baik tenaga sukarela (TSR) maupun korps sukarela (KSR) sejumlah 30 relawan. Teknik digunakan purposive sampling yaitu suatu teknik penetapan sampel dengan cara memilih sampel di antara populasi sesuai dengan yang dikehendaki peneliti (tujuan/ masalah dalam peneitian), sehingga sampel tersebut dapat mewakili karakteristik populasi yang telah dikenal sebelumnya (Nursalam, 2011).

\section{HASIL PENELITIAN}

Secara umum, kesiapsiagaan pedagang pasar dalam penanggulangan bencana kebakaran seperti pada Tabel 1. Berdasarkan Tabel 1 sebagian besar relawan memiliki peran cukup dalam penanggulangan bencana erupsi Gunung Kelud di Kabupaten Blitar sebesar 60\% (18 relawan.

Tabel 2 menunjukkan separuh relawan memiliki peran baik pada saat tidak terjadi bencana erupsi Gunung Kelud sebesar 50\% (15 relawan).

Tabel 3 menunjukkan distribusi frekuensi peran relawan pada saat terjadi bencana di PMI Kabupaten Blitar ( $\mathrm{n}=30)$.

Tabel 4 menunjukkan sebagian besar relawan memiliki peran baik pada saat terjadi bencana erupsi Gunung Kelud sebesar 63,3\% (19 relawan).

Tabel 1. Distribusi Frekuensi Peran Relawan dalam Penanggulangan Bencana Erupsi Gunung Kelud

\begin{tabular}{lcc}
\hline Peran & F & \% \\
\hline Baik & 12 & 40 \\
Cukup & 18 & 60 \\
Kurang & - & - \\
\hline Jumlah & 30 & 100 \\
\hline
\end{tabular}

Tabel 2. Distribusi Frekuensi Peran Relawan Saat Tidak Terjadi Bencana Erupsi Gunung Kelud

\begin{tabular}{lcc}
\hline Peran & F & \% \\
\hline Baik & 15 & 50 \\
Cukup & 10 & 33.3 \\
Kurang & 5 & 16.7 \\
\hline Jumlah & 30 & 100 \\
\hline
\end{tabular}


Tabel 3. Distribusi Frekuensi Peran Relawan pada Saat Terjadi Bencana

\begin{tabular}{lcc}
\hline Peran & F & \% \\
\hline Baik & 19 & 63.3 \\
Cukup & 8 & 26.7 \\
Kurang & 3 & 10 \\
\hline Jumlah & 30 & 100 \\
\hline
\end{tabular}

Tabel 4 menunjukkan sebagian besar relawan memiliki peran kurang pada pasca bencana erupsi Gunung Kelud sebesar 56,7\% (17 relawan).

\section{PEMBAHASAN}

Peran relawan pada saat tidak terjadi bencana dapat dibagi menjadi dua bagian yaitu pada saat mitigasi dan pada saat potensi bencana. Peran relawan pada saat mitigasi adalah penyelenggaraan pelatihan bersama masyarakat, penyuluhan kepada masyarakat, penyediaan informasi kepada masyarakat, peningkatan kewaspadaan masyarakat dan pelatihan simulasi bencana. Sedangkan peran relawan pada saat potensi bencana adalah pemantauan perkembangan ancaman dan kerentanan masyarakat, penyuluhan tanggap darurat, penyediaan dan penyiapan barang pemenuhan kebutuhan dasar, penyediaan dan penyiapan barang, bahan, dan peralatan pemulihan sarana dan prasarana, penyiapan lokasi evakuasi serta peringatan dini (Peraturan Kepala Badan Nasional Penanggulangan Bencana Nomor 17 tahun 2011). Peran relawan pada saat tidak terjadi bencana erupsi Gunung Kelud dilakukan setelah adanya koordinasi dengan BPBD Kabupaten Blitar dalam rangka memperlancar kesiapsiagaan bencana dan mengutamakan keselamatan masyarakat. Peran relawan pada saat tidak terjadi bencana dilakukan pada saat Gunung Kelud berada pada level waspada (level 2) yaitu berdasarkan hasil pengamatan visual dan instrumentasi mulai
Tabel 4. Distribusi Frekuensi Peran Relawan Pasca Bencana Erupsi Gunung Kelud

\begin{tabular}{lcc}
\hline Peran & F & \% \\
\hline Baik & 13 & 43.3 \\
Cukup & - & - \\
Kurang & 17 & 56.7 \\
\hline Jumlah & 30 & 100 \\
\hline
\end{tabular}

terdeteksi gejala perubahan kegiatan, misalnya jumlah gempa vulkanik, suhu kawah (solfatara/ fumarola) meningkat dari nilai normal yang informasinya didapatkan dari PBMVG.

Peran relawan yang baik pada saat tidak terjadi bencana erupsi Gunung Kelud didukung oleh jawaban pertanyaan pada kuesioner ítem pertanyaan nomor 4,9 dan 10 yaitu didapatkan jawaban ya sebesar masing-masing $87 \%$ dan 97\%. Relawan melakukan beberapa kegiatan antara lain memberikan perbekalan kepada masyarakat tentang pengungsian, mengenali tanda-tanda peristiwa, mematuhi setiap ketentuan saat terjadi bencana dan memastikan keberadaan anggota keluarga, menyediakan/menyiapkan bahan, barang, peralatan untuk pemenuhan pemulihan prasarana/sarana berupa logistik dan transportasi serta menyiapkan lokasi evakuasi.

Berdasarkan hasil penelitian peran relawan pada saat terjadi bencana erupsi Gunung Kelud didapatkan relawan memiliki peran baik sebesar 63,3\% (19 relawan), memiliki peran cukup sebesar $26,7 \%$ (8 relawan) dan peran kurang sebesar 10\% (3 relawan).

Peran relawan pada saat terjadi bencana dapat melakukan pencarian, penyelamatan dan evakuasi, penyediaan dapur umum, pemenuhan kebutuhan dasar, penyediaan tempat penampungan/hunian sementara, perlindungan kelompok rentan, perbaikan/ pemulihan darurat, penyediaan sistem informasi dan pendampingan psikosoial korban bencana (Peraturan Kepala Badan Nasional Penanggulangan Bencana Nomor 17 tahun 2011). Pada tahun 2014, erupsi 
Gunung Kelud dianggap lebih dahsyat daripada tahun 1990, meskipun hanya berlangsung tidak lebih daripada dua hari dan memakan 4 korban jiwa bukan akibat langsung letusan. Erupsi pertama yang terjadi merupakan tipe ledakan (eksplosif) yang menyebabkan hujan kerikil yang cukup lebat dirasakan masyarakat. Minimnya korban jiwa merupakan tujuan dari peran relawan pada saat tanggap bencana dan sebelum terjadinya bencana. Penyiapan lokasi evakuasi yang jauh dari titik pusat erupsi dan bahaya dampak erupsi merupakan hal yang sangat penting.

Peran relawan yang baik pada saat terjadi bencana erupsi Gunung Kelud didukung oleh jawaban pertanyaan pada kuesioner ítem pertanyaan nomor 12 dan 18 yaitu didapatkan jawaban ya sebesar masing-masing $90 \%$. Relawan melakukan kegiatan mengkaji wilayah yang terkena bencana, jumlah korban dan kerusakan, kebutuhan sumber daya, ketersediaan sumber daya serta prediksi perkembangan situasi ke depan. Relawan juga melakukan perbaikan/pemulihan darurat untuk kelancaran pasokan kebutuhan dasar kepada korban bencana. Relawan selalu melaporkan kegiatan tersebut kepada PMI selaku induk organisasi yang menaungi dan BPBD Kabupaten Blitar sebagai penanggungjawab dan koordinator kegiatan tanggap darurat.

Berdasarkan hasil penelitian peran relawan pada pasca terjadi bencana erupsi Gunung Kelud didapatkan relawan memiliki peran baik sebesar 43,3\% (13 relawan) dan peran kurang sebesar $56,7 \%$ (17 relawan). Peran relawan pasca terjadi bencana yaitu pengumpulan dan pengelolaan data kerusakan dan rehabilitasi-rekonstruksi fisik dan non-fisik (Peraturan Kepala Badan Nasional Penanggulangan Bencana Nomor 17 tahun 2011). Rehabilitasi dan rekonstruksi fisik dan non-fisik merupakan tugas dari Pemerintah Daerah dan BPBD Kabupaten Blitar sehingga peran relawan disini hanya membantu mendata dan memberikan informasi kepada dua instansi tersebut.

Pada jawaban kuesioner mengenai relawan melakukan pengumpulan dan pengolahan data kerusakan dan kerugian dalam sektor perumahan, infrastruktur, sosial, ekonomi dan lintas sektor pada saat pasca-bencana serta melakukan rehabilitasi-rekonstruksi fisik dan non-fisik dalam masa pemulihan dini pada saat pasca-bencana didapatkan jawaban ya masing-masing $50 \%$. Hal ini memperlihatkan peran relawan terfokus pada pra bencana dan tanggap darurat bencana karena lebih untuk meminimalisasi jatuhnya korban jiwa.

Berdasarkan hasil penelitian peran relawan dalam penanggulangan bencana erupsi Gunung Kelud didapatkan relawan memiliki peran baik sebesar 40\% (12 relawan) dan peran cukup sebesar $60 \%$ (18 relawan). Peran merupakan seperangkat perilaku yang diharapkan dari seseorang yang menduduki suatu posisi atau kedudukan tertentu dalam masyarakat. Peran dijalankan berdasarkan status sosial yang dipilih oleh seorang individu. Peran adalah sesuatu yang diharapkan secara normatif dari seseorang dalam situasi sosial tertentu agar dapat memenuhi harapan-harapan (Setiadi, 2008). Menurut L. Green (1980), dalam Notoatmodjo (2003), ada 3 faktor yang mempengaruhi terbentuknya perilaku yaitu: 1) Faktor predisposisi (predisposing factor), yang mencakup: pengetahuan, nilai, keyakinan, sikap, dan presepsi, berkenan dengan motivasi seseorang atau kelompok untuk bertindak. 2) Faktor pemungkin (enabling factor), yang mencakup: keterampilan dan sumber daya yang perlu untuk perilaku kesehatan. 3) Faktor penguat (reinforcing factor), faktor penguat adalah faktor yang menentukan apakah seseorang memperoleh dukungan atau tidak. Peran relawan yang cukup dalam penelitian ini didukung dari peran relawan pada saat tidak terjadi bencana, pada saat terjadi bencana dan pada pasca bencana erupsi Gunung Kelud. Beberapa hal yang diduga dapat mempengaruhi 
peran yang cukup ini adalah ketrampilan (pelatihan) dan dukungan.

Hasil penelitian menunjukkan sebagian besar relawan mengikuti pelatihan tentang kebencanaan $>2$ kali sebesar $67 \%$ (20 relawan). Keterampilan adalah kemampuan seseorang untuk menjalankan upaya yang menyangkut perilaku yang diharapkan. Kemampuan, ketrampilan, latar belakang keluarga, pengalaman kerja, tingkat sosial dan demografi seseorang mempengaruhi kinerja seseorang. Perilaku terjadi diawali dengan adanya pengalaman-pengalaman seseorang serta faktorfaktor dari luar orang tersebut (lingkungan), baik fisik maupun nonfisik. Kemudian pengalaman dan lingkungan tersebut diketahui, dipersepsikan, diyakini dan sebagainya, sehingga menimbulkan motivasi, niat tersebut yang berupa perilaku (Notoatmodjo, 2003). Adanya keikutsertaan relawan dalam pelatihan kebencanaan tentu akan mampu meningkatkan ketrampilan relawan tersebut. Namun, pelatihan yang ada sebagian besar terfokus pada ketrampilan relawan pada saat tanggap bencana sehingga relawan hanya akan bekerja pada saat terjadinya bencana. Sedangkan untuk pra bencana dan pasca bencana merupakan tugas dan wewenang Pemerintah Daerah melalui BPBD. Hal itulah yang menyebabkan peran relawan menjadi kurang, terutama peran relawan pasca bencana meliputi melakukan pengumpulan dan pengolahan data kerusakan dan kerugian dalam sektor perumahan, infrastruktur, sosial, ekonomi dan lintas sektor pada saat pasca-bencana, melakukan rehabilitasi-rekonstruksi fisik dan non-fisik dalam masa pemulihan dini pada saat pasca-bencana ini merupakan tugas dari Pemerintah Daerah dan BPBD Kabupaten Blitar sehingga peran relawan disini hanya membantu mendata dan memberikan informasi kepada dua instansi tersebut.

Selain itu, dukungan atau motivasi relawan juga dapat mempengaruhiperan relawan dalam penanggulangan bencana. Dukungan atau motivasi relawan bencana dalam melakukan kegiatan kebencanaan adalah faktor kemanusiaan. Dukungan atau motivasi dapat diberikan batasan sebagai proses pemberian dorongan kepada seseorang untuk melakukan aktivitas yang diajukan untuk mencapai beberapa sasaran yang telah ditetapkan. Dukungan dalam hal ini mengacu pada dukungan-dukungan sosial yang dipandang oleh orang sebagai suatu yang dapat diakses (Notoadmodjo, 2003).

Relawan bencana tentunya selalu siap memberikan pertolongan dan bantuan jika diperlukan. Namun, relawan tidak terikat oleh PMI sehingga relawan berhak menolak pada saat mendapat panggilan dari PMI ketika ada bencana. Karena relawan bersifat sukarela sehingga tidak adanya paksaan dari pihak manapun. Seluruh kegiatan kerelawanan merupakan bentuk sukarela dari masing-masing individu karena relawan tidak mendapatkan upah. Relawan bertindak atas dasar rasa kemanusiaan untuk membantu sesama yang memerlukan bantuan. Karena faktor relawan tidak terikat oleh PMI, maka terkadang PMI mengalami kesulitan dalam mengumpulkan relawan yang dapat segera dikirim ke lokasi terjadinya bencana.

\section{PENUTUP}

Berdasarkan penelitian yang telah dilaksanakan dapat disimpulkan peran relawan dalam penanggulangan bencana erupsi gunung kelud di Kabupaten Blitar secara keseluruhan sudah cukup baik.

Saran yang diperoleh dari penelitian ini antara lain 1) meningkatkan peran mahasiswa sebagai relawan baik pada pra bencana, saat bencana, dan pasca bencana, dan bekerjasama dengan PMI maupun BPBD, BNPB untuk mengikutsertakan mahasiswa dalam penangulangan bencana yang ada, terutama erupsi gunung kelud.

Diharapkan relawan PMI untuk mening- 
katkan kerjasama maupun komunikasi dengan BPBD maupun pihak yang terkait agar peran relawan lebih optimal khususnya pada saat pasca bencana.

Diharapkan hasil penelitian ini dapat digunakan sebagai dasar untuk melakukan penelitian tentang menejemen kebencanaan terutama bencana gunung api. Selain itu, peneliti lain diharapkan untuk menambah relawan menjadi responden seperti anggota BPBD dan tanpa memilih responden dengan kiteria relawan yang sudah terlatih, sudah pernah mengikuti pelatian, dan relawan dengan sudah bekerja selama $\geq 1$ tahun. Agar hasil yang di dapat, dapat di bandingkan dengan peran relawan yang belum terlatih, belum pernah mengikuti pelatian, dan relawan yang bekerja $<1$ tahun. Sehingga hasil yang didapat lebih luas dan berfariasi.

\section{DAFTAR PUSTAKA}

Andarmoyo, Sulistyo. (2012). Keperawatan Keluarga. Yogyakarta: Graha Ilmu.

Arikunto, S. (2006). Prosedur Penelitian. Jakarta: Rineka Cipta.

BNPB. (2011). Pedoman Peran Relawan Penanggulangan Bencana.

Friedman, Marilyn, M. (1998). Keperawatan Keluarga. Jakarta: EGC.

Hidayat, A. A. (2008). Riset Keperawatan dan Teknik Penulisan Ilmiah. Jakarta:Salemba Medika.

Hikmawati, E. (2012). Penanganan Dampak Sosial Psikologis Korban Bencana Merapi (Sosial Impact of Psychological Treatment Merapi Disaster Victims). Informasi, Vol. 17, No. 02 Tahun 2012.

Notoatmodjo, S. (2010). Metode Penelitian Kesehatan. Jakarta:Rineka Cipta.

Nursalam. (2011). Konsep dan Penerapan Metode Penelitian Ilmu Keperawatan. Jakarta:Salemba Medika.
Nursalam. (2014). Metodologi Penelitian Ilmu Keperawatan. Jakarta: Salemba Medika.

Pelaksana Harian Badan Koordinasi Nasional Penanganan Bencana (BAKORNAS PB). (2007). Pengenalan Karakteristik Bencana dan Upaya Mitigasinya di Indonesia. Direktorat Mitigasi. Lakhar Bakornas PB.

Peraturan Kepala Badan Nasional Penanggulangan Bencana nomor 17 tahun 2011 Tentang Pedoman Relawan Penanggulangan Bencana.

Pusparini, Yunastiti. (2014). Peran Pemerintah Daerah Terhadap Penanggulangan Korban Bencana Alam Gunung Kelud Di Kecamatan Nglegok Kabupaten Blitar. Fakultas Ekonomi Jurusan Akuntansi Universitas Negeri Surabaya

Sarwidi. (2010). Penanggulangan bencana gunung merapi berdasarkan sistem penanggulangan bencana nasional. Seminar nasional Pengembangan kawasan merapi. DPPM dan MTS UII. Jogjakarta.

Sutomo, A. H., dkk. (2011). Teknik Menyusun KTI-Skripsi-Tesis-Tulisan Ilmiah dalam Jurnal Bidang Kebidanan, Keperawatan dan Kesehatn. Jakarta:Fitramaya.

Ulum, Mochamad Chazienul. (2013). Governance dan Capacity Building Dalam Manajemen Bencana Banjir Di Indonesia. Jurnal Penanggulangan Bencana vol. 4, no. 2 tahun 2013 hal. 5-12.

Undang-Undang Republik Indonesia nomor 24 tahun 2007 Tentang Penanggulangan Bencana.

Winurini, S. (2014). Kontribusi Psychological First Aid (Pfa) dalam Penanganan Korban Bencana Alam. Info Singkat Kesejahteraan Sosial. Vol. VI, No. 03/I/P3DI/ Februari/2014. 